\title{
Effects of cGMP and the nitric oxide donors glyceryl trinitrate and sodium nitroprusside on contractions in vitro of isolated myometrial tissue from pregnant women
}

\author{
J. E. Norman ${ }^{1}$, L. M. Ward ${ }^{1,2}$, W. Martin ${ }^{2}$, A. D. Cameron ${ }^{3}$, \\ J. C. McGrath ${ }^{2}$, I. A. Greer ${ }^{1}$ and I. T. Cameron ${ }^{\mathrm{I}}$ \\ ${ }^{1}$ University of Glasgow, Department of Obstetrics and Gynaecology, Queen Elizabeth Building, \\ Glasgow Royal Infirmary, 10 Alexandra Parade, Glasgow G31 2ER, UK; ${ }^{2}$ Institute of Biomedical and \\ Life Sciences, West Medical Building, University of Glasgow, Glasgow G12 8QQ, UK; and \\ ${ }^{3}$ The Queen Mother's Hospital, Yorkhill, Glasgow G3 8SJ, UK
}

\begin{abstract}
The purpose of this study was to determine the relaxant effects in vitro of two nitric oxide donors, glyceryl trinitrate and sodium nitroprusside, which are currently available for use in vivo, on contractions of non-labouring myometrium from pregnant women. Since nitric oxide also mediates relaxation by increasing the concentration of cGMP, sensitivity to 8-bromo-cGMP (a cGMP analogue) was also determined. The effects of the $\mathrm{K}^{+}$-channel opener lemakalim and of the $\mathrm{Ca}^{2+}$-channel blocker nifedipine were studied for comparison. After the addition of glyceryl trinitrate $\left(0.1-100 \mu \mathrm{mol} \mathrm{l}^{-1}\right)$, sodium nitroprusside $\left(0.1-100 \mu \mathrm{mol} 1^{-1}\right)$ or 8 -bromo-cGMP $\left(0.001-3 \mathrm{mmol} \mathrm{l}^{-1}\right)$, the spontaneous rhythmic contractility of myometrial strips was inhibited in a concentrationdependent manner: the maximum inhibition produced by the highest tested concentration of each drug was $40 \pm 7 \%, 53 \pm 8 \%$ and $39 \pm 8 \%$ of the original degree of contraction, respectively. Myometrial contractions were completely abolished by lemakalim and by nifedipine and verapamil at concentrations of $\geq 10^{-5} \mathrm{~mol} \mathrm{l}^{-1}$. The nitric oxide donors, glyceryl trinitrate and sodium nitroprusside, attenuate myometrial contractions and are therefore useful as tocolytic agents. However, at equimolar concentrations in vitro, the ability of glyceryl trinitrate and sodium nitroprusside to attenuate myometrial contractions is less than that of lemakalin, nifedipine and verapamil. Controlled trials are required to determine the side-effects and clinical efficacy of each of these agents in vivo.
\end{abstract}

\section{Introduction}

Nitric oxide (NO), formed from the guanadino nitrogen of L-arginine by the action of $\mathrm{NO}$ synthase, was originally described as an endothelium-derived vasodilator (Palmer et al., 1987). NO is widely distributed and its many roles include action as a smooth muscle relaxant, a neurotransmitter and as a bactericidal agent (Moncada and Higgs, 1993). In the reproductive tract, NO is implicated in the physiology of menstruation and, during pregnancy, disorders of the $\mathrm{L}$-arginine-NO pathway may contribute to the pathophysiology of preeclampsia and intrauterine growth retardation (Norman and Cameron, 1996). The potential efficacy of $\mathrm{NO}$ as a uterine relaxant has been demonstrated in rats, in which $\mathrm{NO}$ acts as a smooth muscle relaxant in the myometrium. NO inhibits spontaneous contractions in vitro (Yallampalli et al., 1993a); and a reduction in endogenous $\mathrm{NO}$ is implicated in the mechanism of the onset of labour (Yallampalli et al., 1994).

Received 4 November 1996
An agent that effectively inhibits myometrial contractions in women is urgently required for the treatment of preterm labour, a condition that contributes to the premature delivery and death of over 1000 infants in the UK annually (Office of Population Censuses and Surveys, 1993). Two previous studies have suggested that $\mathrm{NO}$ donors inhibit human myometrial contractility (Buhimschi et al., 1995; Lee and Chang, 1995). However, the NO donors used in these studies, diethylamine/ NO, and streptozotocin, which releases NO under ultraviolet radiation, are not currently available for use in vivo. In contrast, glyceryl trinitrate (GTN) and sodium nitroprusside (SNP) are widely used clinically and have been used extensively to treat cardiovascular disease. Furthermore, one of these drugs, GTN, has been used in a preliminary uncontrolled study for the treatment of preterm labour, and is currently undergoing controlled trials for this indication (Lees et al., 1994).

The purpose of the present study was threefold. (1) We aimed to determine the relaxant effect in vitro of GTN and SNP on the myometrium in pregnant women. (2) In order to 
determine the mechanism of action of GTN and SNP, we studied the effect of 8-bromo-cGMP, an analogue of the second messenger cGMP through which NO exerts its actions. To determine the potential confounding effect of endogenous NO production on myometrial contractility, we measured myometrial contractions after adding the $\mathrm{NO}$ synthase inhibitor $N^{\omega}$-nitro-L-arginine methyl ester (L-NAME). (3) In order to determine the potential efficacy of GTN and SNP in comparison with other potential tocolytic agents, the effects of the $\mathrm{K}^{+}$-channel opener lemakalim and of the $\mathrm{Ca}^{2+}$-channel blockers nifedipine and verapamil were also examined. These agents are known to abolish myometrial contractions in vitro when administered in sufficient concentrations (Hollingsworth et al., 1987; Morrison et al., 1993).

\section{Materials and Methods}

\section{Subjects and preparation of tissues}

Women undergoing lower segment Caesarean section at term ( $\geq 37$ weeks gestation) were recruited into the study. All gave their informed consent and the study was approved by our local ethics committee. After the baby and the placenta had been delivered, a strip of myometrium approximately $4 \mathrm{~mm}$ wide was obtained from the upper border of the uterine incision. The myometrium was immediately placed in normal saline at $4^{\circ} \mathrm{C}$. Experiments were performed on tissues within $12 \mathrm{~h}$ of delivery. Myometrium from labouring and non-labouring women was analysed separately.

\section{Methods}

Strips of myometrium $15 \mathrm{~mm}$ long, $2 \mathrm{~mm}$ wide and $2 \mathrm{~mm}$ deep were cut and suspended under a resting tension of $2 \mathrm{~g}$ in organ baths in Krebs' solution at $37^{\circ} \mathrm{C}$ containing $118 \mathrm{mmol}$ $\mathrm{NaCl} \mathrm{l}^{-1}, 4.8 \mathrm{mmol} \mathrm{KCl}^{-1}, 2.5 \mathrm{mmol} \mathrm{CaCl}_{2} \mathrm{l}^{-1}, 1.2 \mathrm{mmol}$ $\mathrm{MgSO}_{4} \mathrm{l}^{-1}, 1.2 \mathrm{mmol} \mathrm{KH}_{2} \mathrm{PO}_{4} \mathrm{l}^{-1}, 24 \mathrm{mmol} \mathrm{NaHCO} \mathrm{l}^{-1}$, and $11.1 \mathrm{mmol}$ glucose $\mathrm{l}^{-1}$, and gassed with $95 \% \mathrm{O}_{2}$ and $5 \%$ $\mathrm{CO}_{2}$. Tension was measured with Grass FTO3 isometric transducers and displayed on a MacLab system. Tissues were equilibrated for $2 \mathrm{~h}$ before drugs were added, during which time most tissues developed stable rhythmic activity (see Results). Drugs were then added in cumulative fashion and their effects on the magnitude and frequency of contractions were assessed. Experiments were performed on more than one strip from each woman; the number of strips and the number of patients used for each experiment are described in the figure legends. A control strip was part of each protocol. A full concentration-response curve was produced from each myometrial strip. Tension in the experimental period was taken as the mean of three consecutive contractions once a steady state had been achieved.

\section{Drugs}

GTN was obtained from Napp Laboratories (Cambridge). 8-Bromoguanosine $3^{\prime}, 5^{\prime}$ cyclic monophosphate sodium salt
(8-bromo-cGMP), nifedipine, SNP and verapamil hydrochloride were obtained from Sigma Chemical Co. (Poole), and lemakalim was a generous gift from $\mathrm{S}$. Trowbridge (SmithKline Beecham Pharmaceuticals, Welwyn Garden City). All drugs were dissolved in saline $(0.9 \% \mathrm{w} / \mathrm{v})$, except for lemakalim, which was prepared as a stock solution of concentration $10 \mathrm{mmol} 1^{-1}$ in $70 \%$ ethanol, and further dilutions were made in saline.

\section{Statistical analysis}

Contractions were quantified by measuring muscle tension in grammes. Once a steady state had been reached, a reduction in the magnitude of spontaneous contractions was expressed as a percentage inhibition (mean $\pm \mathrm{SEM}$ ) of the contraction obtained immediately before the first addition of the drug. The frequency of contractions was measured as the number of contractions $\mathrm{h}^{-1}$. Statistical analysis was carried out using one-way analysis of variance followed by Fisher's PLSD test. A value of $P<0.05$ was considered significant.

\section{Results}

\section{Spontaneous activity of myometrial strips}

When suspended in Krebs' solution, $85 \%$ of myometrial strips (58 of 68 strips from 13 patients) taken from pregnant women at term before labour began developed spontaneous rhythmic activity (Fig. Ia). In a series of ten control strips from ten women, rhythmic activity increased steadily with time to reach a magnitude of $5.1 \pm 1.1 \mathrm{~g}$ and a frequency of $12.7 \pm 1.3$ contractions $\mathrm{h}^{-1}$ within $2 \mathrm{~h}$, and remained constant for at least $3 \mathrm{~h}$ thereafter (Fig. 1b, c). In contrast, only $23 \%$ of myometrial strips (14 out of 62 strips from 12 patients) from labouring women developed rhythmic activity with a mean magnitude and frequency of contractions of $3.3 \pm 0.7 \mathrm{~g}$ and $14.7 \pm 0.8$ contractions $h^{-1}$, respectively. In each group, the figure for mean amplitude and frequency of contractions is derived from the analysis of spontaneously active strips only. The magnitude and frequency of contractions did not differ significantly between myometrial strips obtained from labouring and nonlabouring women. In view of the small proportion of spontaneously contractile myometrial strips obtained from labouring women, it seemed that these strips were not representative of the situation in vivo following the onset of labour. Therefore, further experiments on the effect of each of the test agents were performed on myometrium from non-labouring women only.

\section{Effects of GTN, SNP, 8-bromo cGMP and L-NAME}

The spontaneous rhythmic contractility of myometrial strips was inhibited in a concentration-dependent manner following the addition of GTN $\left(0.1-100 \mu \mathrm{mol} 1^{-1}\right)$, SNP $(0.1-100 \mu \mathrm{mol}$ $\left.\mathrm{1}^{-1}\right)$ and 8-bromo cGMP (0.001-3 $\mathrm{mmol} \mathrm{l}^{-1}$ ) (Figs 1a and 2a). Maximum inhibitions of contractions produced by the highest concentrations of each drug were not significantly different 
(a)
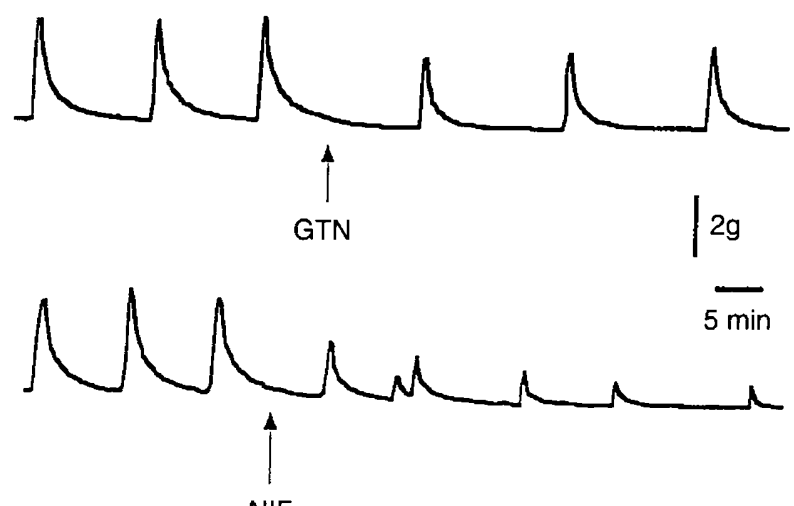

NIF
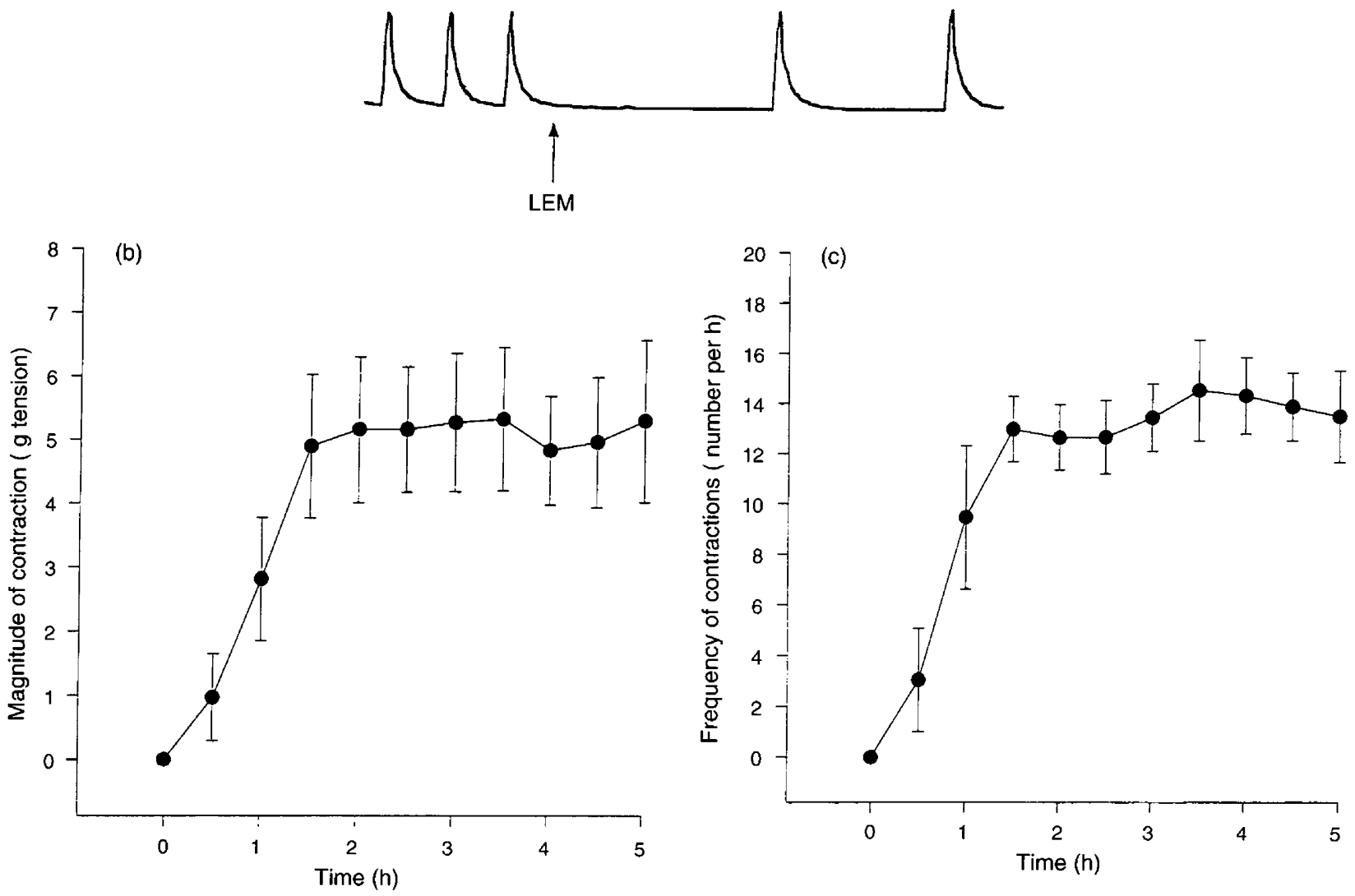

Fig. 1. (a) Individual traces showing the effects of glyceryl trinitrate (GTN; $100 \mu \mathrm{mol}^{-1}$ ), nifedipine (NIF; $0.1 \mu \mathrm{mol} 1^{-1}$ ) and lemakalim (LEM; $30 \mathrm{mmol} \mathrm{l}^{-1}$ ) on the spontaneous rhythmic contractile activity of strips of myometrium from pregnant women. (b,c) Graphs showing the development of spontaneous rhythmic contractile activity of myometrium from pregnant women after suspension in Krebs' solution at $37^{\circ} \mathrm{C}$. The magnitude (b) and frequency (c) increased with time, reaching steady states within $2 \mathrm{~h}$ which were maintained for at least a further $3 \mathrm{~h}$. Each point is the mean \pm SEM of ten observations from ten patients.

and were $40 \pm 7 \%, 53 \pm 8 \%$ and $39 \pm 8 \%$, respectively. GTN caused a slight but significant fall in the frequency of spontaneous contractions at a concentration of $100 \mu \mathrm{mol} \mathrm{l}^{-1}$ (Fig. 2b). SNP increased the frequency of spontaneous contractions at concentrations of $30 \mu \mathrm{mol} \mathrm{I}^{-1}$ and above. 8-Bromo-cGMP had no effect on the frequency of spontaneous contractions (Fig. 2b). The magnitude and frequency of spontaneous contractions was unaffected following treatment with the inhibitor of NO synthase, L-NAME $\left(300 \mu \mathrm{mol} \mathrm{l}^{-1}\right)$ (data not shown).

\section{Effects of verapamil and nifedipine}

The $\mathrm{Ca}^{2+}$-channel blocking agents, nifedipine $(0.01-10 \mu \mathrm{mol}$ $\left.\mathrm{l}^{-1}\right)$ and verapamil $\left(0.01-10 \mu \mathrm{mol} \mathrm{l}^{-1}\right)$, each produced powerful, concentration-dependent inhibition of the magnitude of spontaneous rhythmic contractions (Figs $\mathrm{Ia}$ and $3 \mathrm{a}$ ). The highest concentration of each drug completely suppressed myometrial activity. Both drugs caused an initial increase in the frequency of spontaneous contractions at low concentrations (Fig. 3b). 

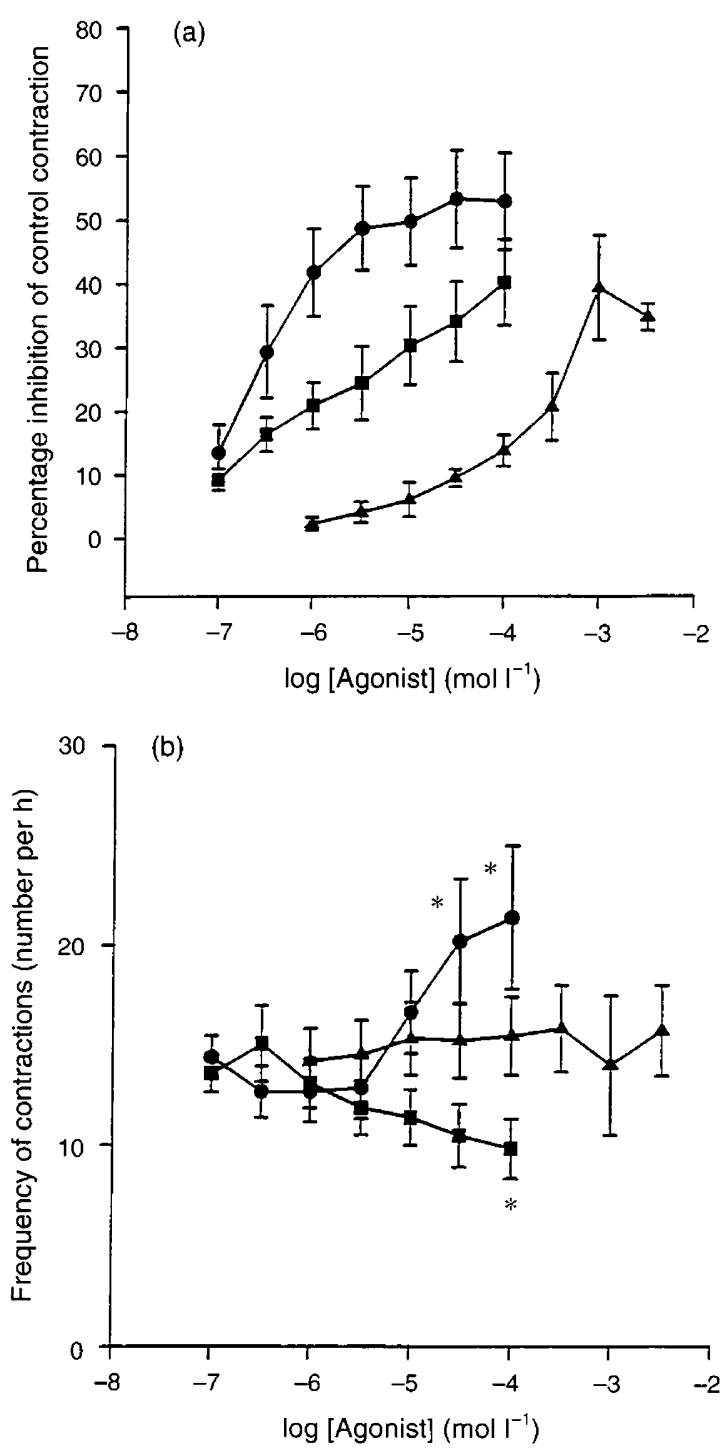

Fig. 2. Concentration-response curves showing the effects of sodium nitroprusside (-), glyceryl trinitrate ( $\boldsymbol{\square}$ ), and 8-bromo-cyclic guanosine monophosphate (8-bromo-cGMP; $\boldsymbol{\nabla}$ ) on (a) the magnitude and (b) the frequency of spontaneous contractions of strips of myometrium from pregnant women. Values are means \pm SEM. Twenty-five strips from nine patients were treated with sodium nitroprusside, 17 strips from five patients were treated with glyceryl trinitrate, and five strips from five patients were treated with 8 -bromo-cGMP. ${ }^{*} P<0.05$ indicates a significant change in the frequency of contractions induced by the drug.

\section{Effects of lemakalim}

At concentrations of $10-30 \mathrm{nmol}^{-1}$, lemakalim had no effect on the magnitude of spontaneous myometrial contractions (Figs la and $4 \mathrm{a}$ ). Higher concentrations ( $\geq 100 \mathrm{nmol} \mathrm{l}^{-1}$ ) led to a progressive fall in the magnitude of spontaneous contractions. At concentrations of $0.01-0.3 \mu \mathrm{mol} 1^{-1}$, lemakalin reduced the frequency of contractions in a concentrationdependent manner (Fig. 4b), with the highest concentration suppressing activity completely.
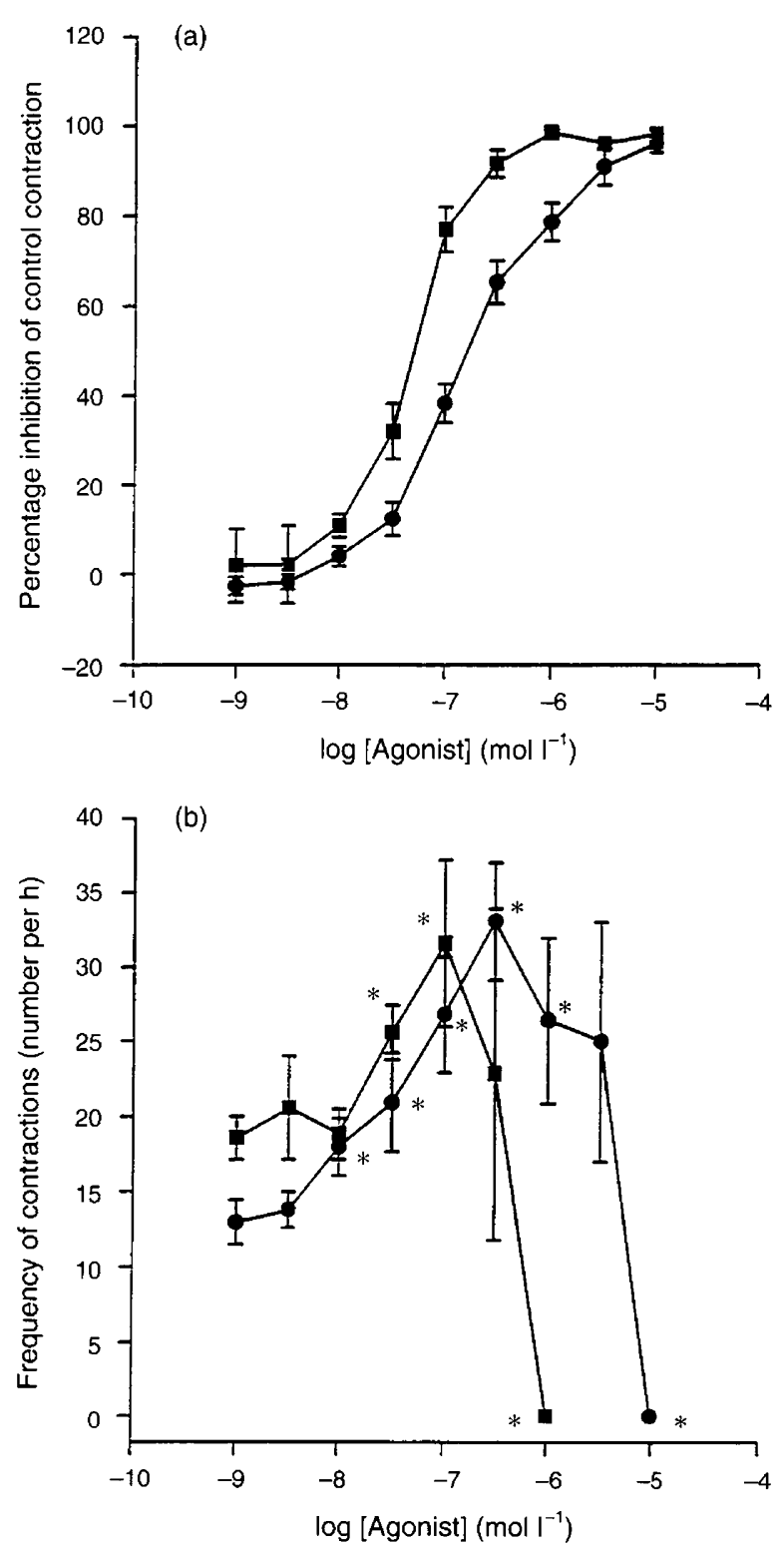

Fig. 3. Concentration-response curves showing the effects of nifedipine (a) and verapamil ( $)$ on (a) the magnitude and (b) the frequency of spontaneous contractions of strips of myometrium from pregnant women. Values are means \pm SEM. Seven strips from five patients were treated with nifedipine and 17 strips from five patients were treated with verapamil. $* P<0.05$ indicates a significant change in the frequency of contractions induced by the drug.

\section{Discussion}

In this study, we have determined the effect in vitro of two commonly available NO donors, GTN and SNP, both of which are used clinically to treat cardiovascular disease. Each of these agents could be used in vivo if found to be effective in inhibiting myometrial contractility in vitro. Indeed, a preliminary uncontrolled study has suggested that GTN may be useful in the treatment of preterm labour (Lees et al., 1994). We are not aware of any other studies to determine the effect of GTN or SNP on contractions of myometrium from pregnant women. However, in the myometrium from non-pregnant 

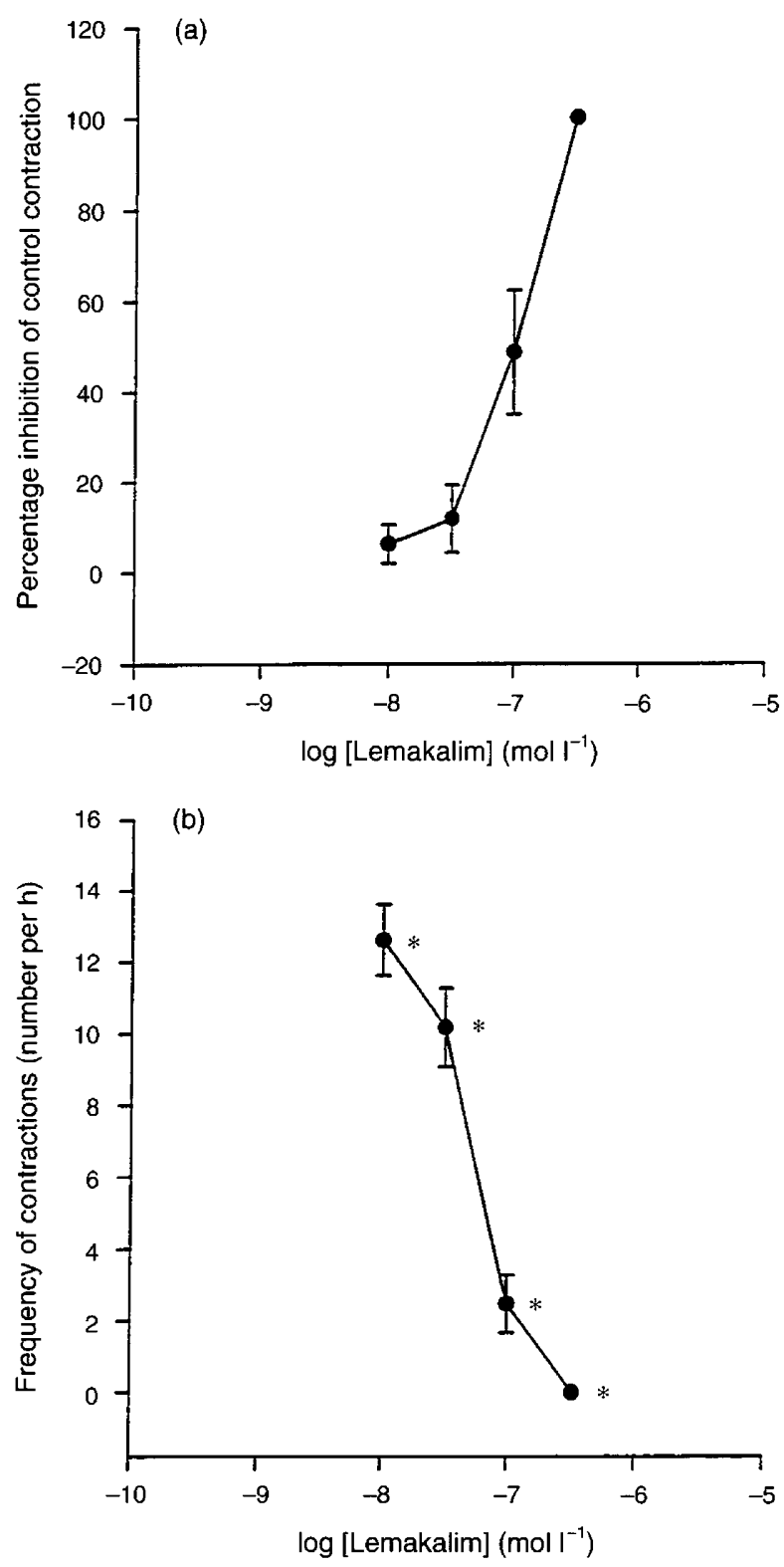

Fig. 4. Concentration-response curves showing the effects of lemakalim on (a) the magnitude and (b) the frequency of spontaneous contractions of strips of myometrium from pregnant women. Each point is the mean \pm SEM of 16 strips from six patients. ${ }^{*} P<0.05$ indicates a significant reduction in the frequency of contractions by lemakalim.

women, SNP at a concentration of $1 \mu \mathrm{mol} 1^{-1}$ caused a $43 \%$ reduction in force and a $55 \%$ reduction in the frequency of spontaneous myometrial contractions (Word et al., 1991). In the present study, GTN $\left(0.1-100 \mu \mathrm{mol} \mathrm{l^{-1 }}\right)$ and SNP $(0.1-$ $100 \mu \mathrm{mol} \mathrm{I}^{-1}$ ) inhibited the spontaneous rhythmic contractility of myometrial strips from pregnant women in a concentrationdependent manner: the maximum inhibition in the magnitude of contractions produced by the highest concentration of each drug was $40 \pm 7 \%$ and $53 \pm 8 \%$ of the control contraction, respectively. The effect on frequency depended on the $\mathrm{NO}$ donor used: GTN caused a decrease in the frequency of contractions at concentrations of $100 \mu \mathrm{mol} \mathrm{l}^{-1}$, whereas
SNP caused an increase in the frequency of contractions at concentrations of $30 \mu \mathrm{mol} \mathrm{l} \mathrm{l}^{-1}$ and above.

The variety of methods for quantifying myometrial activity and for stimulating contractile activity make it difficult to compare results between different studies. However, previous studies of the action of $\mathrm{NO}$ donors in vitro have shown that they inhibit myometrial contractions but fail to abolish contractions completely. The NO-releasing agent dimethylamine/ $\mathrm{NO}$ (at concentrations up to $0.1 \mathrm{mmol} \mathrm{l}^{-1}$ ), causes a maximum reduction of $80 \%$ in the force (area under the curve) of spontaneous contractions in the myometrium of pregnant women (Buhimschi et al., 1995). Furthermore, the generation of $\mathrm{NO}$ from the ultraviolet irradiation of streptozotocin ( $1 \mathrm{mmol}$ $\mathrm{I}^{-1}$ ) reduces the amplitude of myometrial contractions by $50 \%$ and increases the interval between myometrial contractions by a factor of 1.2 (Lee and Chang, 1995).

When studying the effects of NO donors in vitro, it is important to consider their metabolism and mechanism of action. NO donors are thought to exert their major pharmacological effects via the liberation of NO. GTN must be broken down enzymatically before $\mathrm{NO}$ is released; in contrast, SNP and dimethylamine/NO liberate NO spontaneously (Torfgard and Ahlner, 1994; Buhimschi et al., 1995). The enzymes required for the metabolism of organic nitrate esters such as GTN are incompletely defined but are known to be present in a variety of biological tissues such as blood, lung, liver, skeletal muscle and vascular smooth muscle; therefore, we have assumed that these enymes are present in the myometrial strips in vitro. However, if they are absent or occur at reduced concentrations in our system in vitro, the efficacy of GTN in vivo is likely to be greater than that demonstrated in vitro.

The inhibitory effects of GTN and SNP on the amplitude of myometrial contractions was paralleled by 8 -bromo-cGMP in this study. Similar results have been reported previously in the myometrium of pregnant rats (Yallampalli et al., 1993b) but not in that of pregnant women. Our finding that GTN, SNP and 8-bromo-cGMP each produce the same maximum inhibition of the magnitude of contractility supports the assertion that NO donors mediate this effect via an increase in the intracellular concentration of cGMP. GTN and SNP displayed different effects on the frequency of contractions: GTN inhibited contraction frequency while SNP stimulated it. The reasons for this result remain obscure but could be related to different mechanisms of action of SNP and GTN. Since cGMP had no effect on the frequency of uterine contractions, the observed effect of SNP and GTN on this parameter is unlikely to be mediated via cGMP. Several effects of NO as a smooth muscle relaxant that are not dependent on cGMP have been observed, the most important of which is probably the activation of $\mathrm{K}^{+}$channels (Bolotina et al., 1994). Both SNP and GTN have been shown to activate charybdotoxin-sensitive $\mathrm{K}^{+}$channels, and GTN also displays other relaxant effects that are not sensitive to charybotoxin (Hamaguchi et al., 1992). Although these data help to explain the inhibitory effects of GTN on the frequency of myometrial contractions, the reason for the SNP-induced increase is unknown. A stimulatory effect of SNP on the frequency of contractions has also been described in rat myometrium (Franchi et al., 1994), although this agent has previously been shown to inhibit the frequency of contractions in the myometrium from non-pregnant women (Word et al., 1991). Further 
work is required to investigate the mechanisms behind the SNP-induced changes in myometrial contractile frequency.

The concept that the myometrium itself produces $\mathrm{NO}$ is suggested by data showing that the myometrium from pregnant women contains CGMP and produces nitrate and nitrite in culture (Buhimschi et al., 1995). The effect of endogenous NO production within the myometrium was determined by applying L-NAME, an inhibitor of NO synthesis, to myometrial strips. In our experiments, L-NAME $\left(0.3 \mathrm{mmol} \mathrm{I}^{-1}\right)$ had no effect on myometrial contractions, implying that there is no endogenous $\mathrm{NO}$ production within the myometrium in vitro. These results are in agreement with data reported by Jones and Poston (1997). In contrast, a modest increase in the contractions of myometrium from pregnant women occurred in response to the NO synthase inhibitor $N^{\text {ro }}$-nitro-L-arginine (L-NNA) at concentrations of $0.3 \mathrm{mmol} \mathrm{l}^{-1}$ (Lee and Chang, 1995) and in the contractions of myometrium from nonpregnant women in response to L-NAME $\left(1 \mathrm{mmol} \mathrm{l}^{-1}\right)$ or L-NNA $\left(1 \mathrm{mmol} \mathrm{l}^{-1}\right.$ ) (Buhimschi et al., 1995). The different results obtained by these studies might be due to differences in sampling technique. It is possible that in cases where an increase in contractility to $\mathrm{NO}$ synthase inhibitors can be demonstrated, the myometrial strips being tested are attached to small amounts of NO-generating tissue (for example, endometrium or decidua). Alternatively, myometrial biopsies taken from different areas of the uterus may differ in their NO-generating ability; thus, if myometrium is taken from an area where minimal amounts of NO are generated, then L-NAME would not be expected to have any effect.

The third aim of this study was to determine the potential efficacy of GTN and SNP in attenuating myometrial contractions in comparison with other potential tocolytic agents such as $\mathrm{Ca}^{2+}$-channel blockers and $\mathrm{K}^{+}$-channel openers. Preliminary clinical studies using $\mathrm{Ca}^{2+}$-channel openers to treat preterm labour (Ferguson et al., 1990) have shown that these agents could be beneficial, but further research is required to determine their effects on mother and fetus. The $\mathrm{K}^{+}$-channel opener lemakalim has been shown to be effective in inhibiting human myometrial contractions in vitro. Studies with diazoxide, which is now known to exert its actions via $\mathrm{K}^{+}$-channel opening, have suggested that it might be useful in treating preterm labour (Caritis et al., 1979; Morrison et al., 1993). In the studies described here, complete inhibition of myometrial contractions was achieved using nifedipine, verapamil or lemakalim. In contrast, no NO donor, including those described here, can inhibit contractions completely in vitro. Clearly, the side-effects and efficacy of each of these agents must be determined in vivo. However, the available data from studies in vitro indicate that nifedipine, verapamil and lemakalim may each be more effective than NO donors in the treatment of preterm labour.

These data suggest that controlled clinical trials of each of the NO donors GTN and SNP, the $\mathrm{Ca}^{2+}$-channel blockers nifedipine and verapamil and the $\mathrm{K}^{+}$-channel opener lemakalim are warranted in the treatment of preterm labour. The sideeffects and efficacy of each of these agents must be studied in vivo. If it is found that these drugs are as effective in attenuating contractions of the myometrium of labouring women in vivo as they are in vitro in myometrium removed before the onset of labour, they could have a major impact in reducing perinatal mortality and morbidity.
This work was supported by grants from Yorkhill National Health Service Trust, Tenovus UK, the Medical Research Council (G9437277) and Wellbeing (the research arm of the Royal College of Obstetricians and Gynaecologists), for which the authors are very grateful.

\section{References}

Bolotina VM, Najibi S, Palacino JJ, Pagano PJ and Cohen RA (1994) Nitric oxide directly activates calcium-dependent potassium channels in vascular smooth muscle Nature $368850-853$

Buhimschi I, Yallampalli C, Dong Y-L and Garfield RE (1995) Involvement of a nitric-oxide guanosine monophosphate pathway in control of human uterine contractility during pregnancy American Journal of Obstetrics and Gynecology 172 1577-1584

Caritis SN, Edelstone DI and Mueller-Heubach E (1979) Pharmacologic inhibition of preterm labor American Journal of Obstetrics and Gynecology 133 557-578

Ferguson JE, Dyson DC, Schutz T and Stevenson DK (1990) A comparison of tocolysis with nifedipine or ritodrine: analysis of efficacy and maternal, fetal, and neonatal outcome American journal of Obstetrics and Gynecology 163 105-111

Franchi AM, Chaud M, Rettori V, Suburo A and McCann SM (1994) Role of nitric oxide in eicosanoid synthesis and uterine motility in estrogen-treated rat uteri Proceedings of the National Academy of Sciences USA 91 539-543

Hamaguchi M, Ishibashi T and Imai S (1992) Involvement of charybdotoxinsensitive $\mathrm{K}^{+}$channel in the relaxation of bovine tracheal smooth muscle by glyceryl trinitrate and sodium nitroprusside Journal of Pharmacology and Experimental Therapeutics 262 263-270

Hollingsworth M, Edwards D and Donnai P (1987) Inhibition of contractions of the isolated pregnant human myometrium by calcium entry blockers Medical Science Research 15 15-16

Jones G and Poston L (1997) The role of endogenous nitric oxide synthesis in contractility of term or preterm human myometrium British Journal of Obstetrics and Gynaecology 104 241-245

Lee JH and Chang KC (1995) Different sensitivity to nitric oxide of human pregnant and nonpregnant myometrial contractility Pharmacology Communications 5 147-154

Lees C, Campbell S, Jauniaux E, Brown R, Ramsay B, Gibb D, Moncada S and Martin JF (1994) Arrest of preterm labour and prolongation of gestation with glyceryl trinitrate, a nitric oxide donor Lancet 43 1325-1326

Moncada S and Higgs A (1993) The L-arginine-nitric oxide pathway The New England Journal of Medicine 3292002-2012

Morrison JJ, Ashford MLJ, Khan RN and Smith SK (1993) The effects of potassium channel openers on isolated pregnant human myometrium before and after the onset of labor: potential for tocolysis American Journal of Obstetrics and Gynecology 169 1277-1285

Norman JE and Cameron IT (1996) Nitric oxide in the human uterus Reviews of Reproduction 1 61-68

Office of Population Censuses and Surveys (1993) Perinatal and infant: social and biological factors Mortality Statistics DH3 No. 25 23-26

Palmer RMJ, Ferrige AG and Moncada S (1987) Nitric oxide release accounts for the biological acitivity of endothelium-derived relaxing factor Nature 327 $524-526$

Rodriguez-Escudero FJ, Aranguren G and Benito JA (1981) Verapamil to inhibit the cardiovascular effects of ritodrine International journal of Gynaecology and Obstetrics $19333-336$

Torfgard KE and Ahlner J (1994) Mechanisms of action of nitrates Cardiovascular Drugs and Therapy 8 701-717

Word RA, Casey ML, Kamm KE and Stull JT (1991) Effects of cGMP on $\left[\mathrm{Ca}^{2+}\right]_{\mathrm{i}^{\prime}}$ myosin light chain phosphorylation, and contraction in human myometrium American Journal of Physiology 260 C861-C867

Yallampalli C, Garfield RE and Byam-Smith M (1993a) Nitric oxide inhibits uterine contractility during pregnancy but not during delivery Endocrinology 133 1899-1902

Yallampalli C, Izumi H, Byam-Smith M and Garfield RE (1993b) An L-argininenitric oxide-cyclic guanosine monophosphate system exists in the uterus and inhibits contractility during pregnancy American Journal of Obstetrics and Gynecology 170 175-185

Yallampalli C, Byam-Smith M, Nelson SO and Garfield RE (1994) Steroid hormones modulate the production of nitric oxide and cGMP in the rat uterus Endocrinology 134 1971-1974

Downloaded from Bioscientifica.com at 04/26/2023 01:20:59PM 